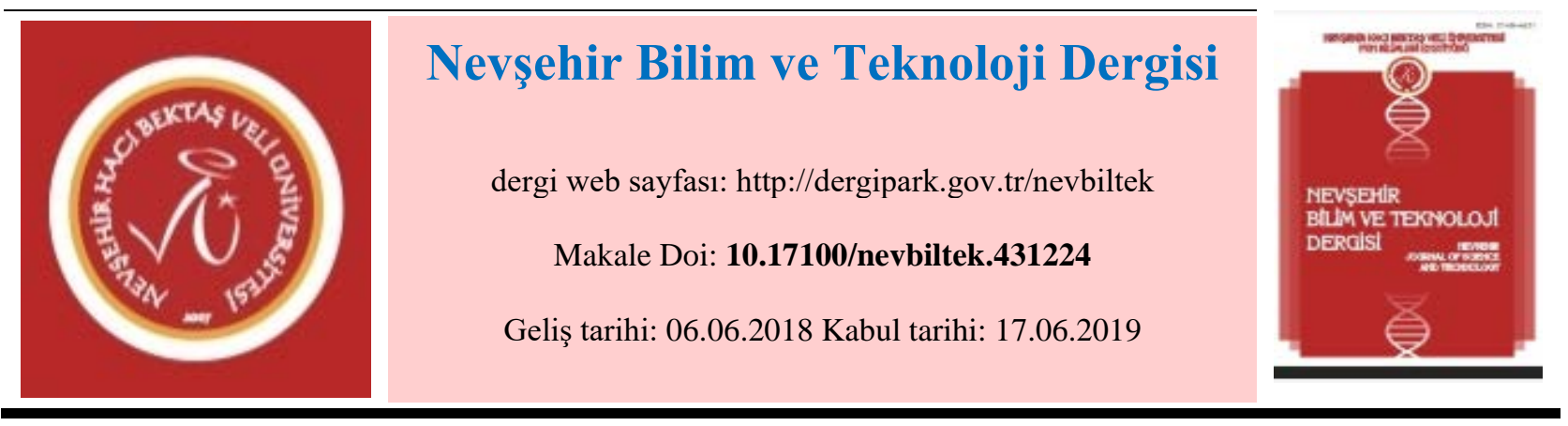

\title{
Çevre Mühendisliğinde Su Arıtımında Ultrases Uygulamaları
}

\author{
Şennur Merve YAKUT*1 \\ Nevşehir Hacı Bektaş Veli Üniversitesi, Mühendislik Mimarlık Fakültesi, Çevre Mühendisliği Bölümü, Nevşehir \\ ORCID ID: 0000-0001-9190-4061
}

Öz

Son yıllarda artan endüstrileşme sonucunda, üretim faaliyetlerinin artması, beraberinde çevre açısından sorunlar getirmektedir. Bu sorunların temeli olarak su kirliliği görülmektedir. Su kirliliğinin çevre açısından sorun olarak görülmesinden beri birçok arıtım yöntemi üzerinde çalışmalar yapılmaktadır. Bu yöntemlerden biri de son yıllarda üzerinde farklı modifikasyonlarla çalışmalar yapılmaya başlanılmış olan ultrases ışınımlı proseslerdir. Ultrases ışınımında kavitasyon adı verilen olay gerçekleşir. Kavitasyon olayı sonucunda oluşan yüksek basınç ve sıcaklık sonucunda ortamda hidroksil radikalleri oluşur ve bu radikaller suyun içerisindeki kirleticilerin giderilmesini sağlar. Ultrases etkili ve uygulanabilir yapısı nedeniyle iyi bir teknolojidir. Ancak, ultrases ışınımı, tek başına çok etkili olmamasından dolayı genellikle başka proseslerle kombine edilerek (adsorbsiyon, fenton, enzim gibi) çalışılmaktadır. Ultrases 1şııımının verimi yükselttiği çalışmalar literatürde oldukça çoktur. Ultrases 1şınımının çevre mühendisliği uygulamaları literatürde çoğunlukla boyar madde giderimi üzerine olarak göze çarpsa da başka alanlarda da (alg giderimi, zararlı organik bileşiklerin bozundurulması gibi) uygulamaları mevcuttur.

Anahtar Kelimeler: Atıksu Arıtımı, Atıksu, Ultrases..

\section{Ultrasound Applications About Water Treatment in Environmental Engineering}

\section{Abstract}

As a result of increased industrialization in recent years, the increase of production activities brings environment problems. Water pollution is seen as the main cause of these problems. Since water pollution is regarded as a problem in terms of environment, many methods of treatment have been carried out. One of these methods is ultrasound radiation processes, which have started to work on different modifications over the last few years. In ultrasound radiation, the cavitation occurs. The high pressure and temperature generated as a result of cavitation together with the formation of hydroxyl radicals in the environment, these radicals can remove pollutants in the water. Ultrasound is a good technology because of its efficient and applicable structure. Because ultrasound radiation is not very effective on its own, it is usually studied in combination with other processes (such as adsorption, fenton, enzyme). Also, the studies in which ultrasound radiation increases the efficiency are very much in the literature. Environmental engineering applications of ultrasound radiation are mostly based on the removal of the dye, but there are also applications in other areas (such as degradation of algae, degradation of harmful organic compounds).

Keywords: Ultrasound, Wastewater, Water treatment.

1 e-mail:sennurmerve@nevsehir.edu.tr 


\section{Giriş}

Ses, yayılabilme imkanı bulunan bir çevrede sıkışma ve gevşemeye sebep olan belli frekanslarla hareket eden (dalga şeklinde ilerleyen) mekanik bir enerji olarak tanımlanmaktadır. " Ses frekans birimi olarak Hertz (Hz) kabul edilmektedir. Hertz bir saniyedeki dalga sayısı olarak tanımlanmaktadır; yani saniyede 1 dalga $1 \mathrm{~Hz}, 1000$ dalga 1 kiloHertz (KHz), 1 milyon dalga da 1 megaHertz (MHz) demektir ” [1].

Su arıtımında $20 \mathrm{kHz}$ veya daha yüksek ses kullanılması, ultrases, diğer bir değişle "sonikasyon" olarak adlandırılmaktadır. Bu dalgalardaki enerji kavitasyon prensibine göre dağılmaktadır. Kavitasyonda kısa süre aralıklarında oluşan baloncuklar büyür, boşluklar oluşur ya da çökelir [2]. Kavitasyon, zıt basınç uygulandığında oluşan mikro baloncukların bir sonucu olarak da tanımlanabilmektedir. Sıvı ortama ihtiyaç duyulabilecek büyüklükte negatif bir basınç uygulandığında, moleküllerinin arasındaki uzaklık, sıvıyı kaldırma amaçlı aşı1ır ve böylece sıvı bozulup boşluklar oluşmuş olur [3].

Ultrasonik dalgaların odaklanabilme, yansıyabilme gibi özellikleri elektromanyetik dalgalara benzemektedir. Ancak, elektromanyetik dalgaların aksine, yayılmaları için esnek bir ortama ihtiyaç duymaktadırlar ve bu akustik enerji, moleküller tarafından içine alınamamaktadır [4].

Sonikasyon, disiplinler arası uygulamalarının yanı sıra zehirli ve tehlikeli bileşiklerin kirlenmiş sudan uzaklaştırılmasında da kullanıma sahiptir. Sonikasyon uygulamalarıyla ortamda hem yüksek oksitleme kapasitesine sahip radikaller oluşmakta hem de baloncuklardaki uçucu hidrofobik bileşiklerin termal ayrışması gerçekleşmektedir [5].

Sonikasyon olayında gerçekleşen kimyasal olaylarla ilgili olarak dört teori belirtilmektedir. Bunlar; i) sıcak nokta, ii) elektrik alan, iii) plazma, iv) süperkritik teorisi. Sıcak nokta (hot-spot) teorisi, baloncukların patlamasıyla yüksek basınç (1000 atm) ve yüksek sıcaklık $\left(5000 \mathrm{~K}^{\circ}\right)$ oluşmasından söz etmektedir. Elektrik teorisinde, baloncukların parçalanmasıyla yüksek bir elektrik alan farkı oluşması ve buna bağlı olarak bağların kırılmasına dayanmaktadır. Plazma alan teorisinde, baloncuklar içinde mikroplazmalar oluşmaktadır. Süperkritik teoride, ortam şartları suyun kritik koşullarının üstünde $\left(674 \mathrm{~K}^{\circ}, 22.1 \mathrm{MPa}\right)$ olmakta ve baloncukların parçalanmasıyla süper kritik su oluşumu gerçekleşmektedir [6]. Eşitlik ( 1-10)'da ultrases ile gerçekleşen, suyun bozunma reaksiyonları verilmiştir [7] :

$$
\begin{aligned}
& \cdot \mathrm{OH}+\cdot \cdot \mathrm{OH} \rightarrow \mathrm{H}_{2} \mathrm{O}_{2} \\
& \cdot \mathrm{OH}+\cdot \cdot \mathrm{OH} \rightarrow \mathrm{H}_{2} \mathrm{O}+\mathrm{O} \\
& \cdot \mathrm{OH}+\cdot \mathrm{OH} \rightarrow \mathrm{H}_{2}+\mathrm{O}_{2} \\
& \cdot \mathrm{H}+\mathrm{O}_{2} \rightarrow \cdot \mathrm{HO}_{2} \\
& \cdot \mathrm{HO}_{2}+\cdot \cdot \mathrm{H} \rightarrow \cdot \mathrm{H}_{2} \mathrm{O}_{2} \\
& \cdot \mathrm{HO}_{2}+\cdot \mathrm{HO}_{2} \rightarrow \mathrm{H}_{2} \mathrm{O}_{2}+\mathrm{O}_{2} \\
& \cdot \mathrm{OH}+\mathrm{H}_{2} \mathrm{O} \rightarrow \mathrm{H}_{2} \mathrm{O}_{2}+\mathrm{O} \\
& \cdot \mathrm{H}_{2} \mathrm{O}+\cdot \cdot \mathrm{O} \rightarrow \mathrm{H}_{2} \mathrm{O}_{2} \\
& \cdot \mathrm{H}+\cdot \cdot \mathrm{H} \rightarrow \mathrm{H}_{2} \\
& \cdot \mathrm{H}+\cdot \cdot \mathrm{OH} \rightarrow \mathrm{H}_{2} \mathrm{O}
\end{aligned}
$$

Bu çalışmada, insan ve diğer canlı ortamları için büyük sorun teşkil eden atıksuların arıtımında kullanılan, bir ileri oksidasyon yöntemi olan ultrases uygulamasının farklı kullanım alanlarının araştırılması üzerine değerlendirmeler yapılmıştır. 


\section{Atıksuların Arıtımında Kullanılan Ultrases Uygulamaları}

Ultrasesin etkileri son yıllarda karşımıza sıklıkla çıkmasına rağmen aslında bu terim günümüzden çok öncesinde araştırılmaya başlanılmıştır. Kirleticilerin artımındaki yeteneği ve diğer proseslerle kombine edilmesiyle ortaya çıkan yüksek oksidasyon verimiyle bilim dünyasında oldukça dikkat çekmektedir. Ayrıca ultrases, çoğu zaman fazladan bir kimyasal kullanımı gerektirmemesi ve çevreye olumsuz ilave bir etkide bulunmamasından dolayı da bir ileri oksidasyon prosesi olarak tercih edilme sebebi olmaktadır.

Ultrases ışınımı (US) tek başına kullanılabildiği gibi kirlilik verimini arttırma amaçlı başka proseslerle birlikte ya da ön arıtma olarak kullanılabilmektedir. Bu derleme makalesinde, ultrases 1şınımının kullanıldığı bazı prosesler ele alınacaktır.

\subsection{Yalnız Ultrases ile Oksidasyon}

Ultrases, daha az ekstrem koşullarda (az kimyasal kullanımı gibi) daha iyi verim elde edilmesinden dolayı tercih edilmektedir. Burada geçekleşen kavitasyon sonucunda; kütle transferi gerçekleşmesinin sağlanması, yüksek katalizör verimi eldesi, reaksiyon için yararlı reaktif oluşumu ve reaksiyon aşamalarının azalması gibi verimi artırıcı etkenler gerçekleşmektedir [4].

Gümüşdere [8] yaptığı çalışmasında, ses ötesi dalgalar kullanarak, 6 saat boyunca $20 \mathrm{kHz}$ frekansında, Reactive Red 2, Reactive Blue 4, Basic Yellow 2 boyarmaddeleri giderimi için uygulama yapmıştır. Sonuç olarak, Reactive Red 2 ile yüksek bozunma elde etmiş olup, Basic Yellow 2 boyasının 5 saat sonunda tamamen gideriminin sağlandığını tespit etmiştir.

Mason ve ark. [9], ultrases ile bacillus subtilis giderimi için $27 \mathrm{kHz}$ frekansta ultrases ile çalışmışlardır. Martin Walter itme-çekme sistemi kullanarak CFU seviyesini 1 saatte \% 70 oranında azaltmışlar ancak daha yüksek frekanslarda (Undatim Sonoxide sistemi) ancak 5 günde \% 85 azalma sağlandığını görmüşlerdir.

Estevez- Calvar ve ark. [10], 3 farklı zooplanktoniğin (A. Amphitrite, B. Plicatilis, A. Salina) balast suyundan arıtımında 20-22 kHz frekanslarında ultrases uygulamışlar ve \% 93-95'lik zooplankton (B. plicatilis ve A. Salina) ölümü sağlandığını rapor etmişlerdir.

\section{2. $\mathrm{US}+\mathrm{H}_{2} \mathrm{O}_{2} / \mathrm{O}_{3}$}

Ultrases 1şınımının yanında hidrojen peroksit ya da ozon kullanıldığında, ortamda ilave serbest radikaller oluşumu artacak ve beraberinde kirletici maddelerin bozulma oranı artacaktır. Aynı zamanda; pH, reaktördeki türbülans yoğunluğu, kirletici maddenin yapısı, kirleticinin suyu sevip sevmeme yapısı ve kirletici madde yoğunluğu gibi parametreler bu proseslerde önemlidir. Eşitlik 11'de görüldüğü üzere hidrojen peroksit ayrışırken aynı zamanda ortamda bulunan hidroksil radikallerini de süpürücü etki yapmaktadir [11].

$\mathrm{OH} \bullet+\mathrm{H}_{2} \mathrm{O}_{2} \rightarrow \mathrm{H}_{2} \mathrm{O}+\mathrm{HO}_{2} \bullet$

Jing ve ark.[12], UV gücü, $73 \mathrm{~W}$, US gücü; 142,5 W, O3 akış hızı 10,75 gh $^{-1}$ olarak belirledikleri sistemde, yanıt yüzey metodolojisi ve Monte Carlo simülasyon destekli yapay sinir ağları kullanımı ile gerçekleştirdikleri çalışmalarında Atrazin üretim suyunun arıtımında \% 97.58 'lik verim elde etmişlerdir.

Jawale ve ark. [13], Potasyum ferrosiyanit (KFC) içeren atıksuyun ileri oksidasyon ile arıtım yaptıkları bir çalışmada, $\mathrm{H}_{2} \mathrm{O}_{2}, \mathrm{H}_{2} \mathrm{O}_{2}+\mathrm{TiO}_{2}, \mathrm{O}_{3}, \quad \mathrm{US}+\mathrm{UV}+\mathrm{O}_{3}$ ile arıtım çalışmaları 
gerçekleştirmişlerdir. US ile kombine edilen bu proseslerde sırasıyla; \% 54.2, \% 74.82, \% 82.43 verim elde edilmiş olup en yüksek verim \% 92.47 ile US+ UV+ $\mathrm{O}_{3}$ kombinesiyle elde edilmiştir.

Guo ve ark. [14], Sülfametoksazol parçalanmasında US, $\mathrm{O}_{3}$ ve US $+\mathrm{O}_{3}$ kullanımı gerçekleştirmişlerdir. Reaksiyon oranının \% 6-26’ya arttığı ve S- N bağının bölünmesinin sağlanması gerçekleşmiştir.

Barik ve Gogate [15], 2,4 diklorofenolün katalizör ve US $+\mathrm{O}_{3}$ kullanılarak bozunması amaçlananan çalışmalarında, katalizör olarak $\mathrm{ZnO}$ ve $\mathrm{CuO}$ kullanmışlardır. Sadece US ile \% 28.85 bozunma, US + $\mathrm{O}_{3}+$ $\mathrm{ZnO}$ ile \% 95.66 bozunma ve $\mathrm{US}+\mathrm{O}_{3}+\mathrm{CuO}$ ile \% 97.03 bozunma ile sonuç almışlardır.

\subsection{Sonofotokatalitik Oksidasyon}

Fotokatalitik ve ultrases yöntemi ayrı ayrı ele alındığında iki yöntemin de kirletici madde gideriminde uygun oldukları görülmektedir. İki yöntem birleştirildiğinde, reaksiyon için daha çok miktarda serbest radikal üretimi sağlanmaktadır. Bu yöntemde muhtemel durumlar; sıcak-nokta teorisine göre gerçekleşen sicaklık ve basınç artışı, akustik mikro-akış sebebiyle titanyum dioksit gibi katalizör malzemelerin yüzeyinin süpürülmesi ve katalizörün etkisinin artırılması, katalist yüzeyinin şok dalgalarıyla artırılması, kavitasyondan kaynaklı ara ürünlerin kirleticileri arıtılması, organik substratın 1şık yayan porlarla ve elektronlarla tepkimeye girmesi şeklinde olmaktadır [11].

Bire [7], Direct-Red 23 boyasının katalizör olarak çinko oksit kullanımıyla degredasyonu üzerine gerçekleştirdiği bir çalışmasında, 1 g/L ZnO, 132 Watt/ m² UV şiddeti, 50 Hertz dalga genliği kullanarak, Yalnız ultrases ile \% 57 boya degredasyonu, katalizör ve UV ilavesiyle \% 85 boya degredasyonu sağlamıştır.

Nakajima ve ark. [16], 1,4-dioksanın sudan ayrışması için sonofotokataliz yöntemi kullanmışlardır. Katalizör olarak $\mathrm{TiO}_{2}$ ve hidrofulorik asit $+\mathrm{TiO}_{2}$ uygulaması yapmışlardır. Sonuçta, $\mathrm{HF}+\mathrm{TiO}$ katalizörü, etilen glikol diformat ve 1,4- dioksanın adsorblanma kapasitesini arttırmıştır.

Reddy ve ark. [17], nefto mavi siyah boyası içeren gerçek tekstil atıksuyunun sonofotokatalitik arıtımı üzerine çalışmalar gerçekleştirmişlerdir. İzleyici parametreler olarak ise, pH, gaz içeriği, $\mathrm{H}_{2} \mathrm{O}_{2}$ konsantrasyonu ve katalizör yükleme etkisini seçmişlerdir. Sonuçta, 1:7 Fe: $\mathrm{TiO}_{2}$ oranında \% 96 giderim verimi ve gerçek tekstil atıksuyunda aynı $\mathrm{Fe}: \mathrm{TiO}_{2}$ oranında \% 91 TOK giderimi sağlamışlardır.

Verma ve ark. [18], 4-kloro- 2 nitrofenol degredasyonu amaçlı gerçekleştirdikleri çalışmalarında, UV gücü, 125 Watt ve US gücü $100 \mathrm{~W}$, frekansı $33+3 \mathrm{kHz}$ değerlerinde KOİ gideriminde \% 96 oranını elde etmişlerdir.

\section{5. Ön arıtımda Ultrases}

Ultrases bazı durumlarda bir ön arıtma yöntemi olarak kullanılmaktadır. Suda çözünebilen maddeler hidroksil radikalleriyle tepkimeye girerek yükseltgenmektedirler. Bir çalışmada, arsenik arıtımında, suya fazladan kimyasal ilavesi olmaksızın sadece ultrases 1şınımı verildiğinde As +3 ‘ün, As +5' e okside olduğu görülmüştür. +3 değerlikli arsenit, +5 değerlikli arsenata göre daha kolay giderilebildiği için ultrases bir ön arıtım tekniği olarak kullanılabilmektedir [24]. (+3) değerlikli arseniğin ultrases sonucu ortaya çıkan hidroksil radikalleriyle tepkimesi (eşitlik 14) aşağıda gösterilmektedir [25] :

$\mathrm{As}(\mathrm{III})+\mathrm{HO} \rightarrow \mathrm{As}(\mathrm{IV})+\mathrm{HO}^{-}$ 
Bargezar ve ark. [26], Klorofenolün, US/ Peroksimonosülfat (PMS)/Nano boyutta sıfır demir iyonu (nZVI) ile giderimi üzerine çalışmışlardır ( $\mathrm{pH}=3$, nZVI= $0.4 \mathrm{~g} / \mathrm{L}, \mathrm{PMS}=1.25 \mathrm{mM}$, US = $200 \mathrm{~W}) .4-$ klorofenolün 30 dakikada \% 95'inin bozunduğunu tespit etmişlerdir. Ayrıca gerçek bir petrokimyasal atıksuyla çalıştıklarında biyolojik arıtma için uygun bir ön arıtma olduğunu görmüşlerdir.

Gonze ve ark. [27], klasik biyolojik arıtma öncesi ön arıtma NaPCP, bakteriler ve su pireleri üzerindeki toksisite ve kirletici bozunma etkisi incelenmiştir. Deneysel sonuçlar, ultrasonik arıtımın verimli bir preoksidasyon aşaması olduğunu göstermiştir.

Khaire ve Gogate [28], süt endüstrisi atıksularından protein ve laktozun geri kazanımı için termal, sonikasyon ve termosonikasyon metotları incelemişlerdir. Ultrasesli ısıtma ile birlikte kullanılan ön işlemler sonucunda, peynir altı suyundan laktozun verimli bir şekilde geri kazanıldığı tespit edilmiştir.

\subsection{US + Adsorpsiyon}

Adsorpsiyon tekniğiyle ultrases 1şınımının birleştirilmesi de günümüzde oldukça popülerdir. Ultrasonik ışınımların mekanik etkisi ile adsorban maddelerin yüzey alanının arttırılması, adsorpsiyon verimini ve dolayısıyla kirletici giderimini arttırmaktadır [29].

Şayan [30], US destekli adsorbsiyon ile renk ve KOİ giderimi üzerine çalışmıştır. Boyar madde olarak rifacion yellow (HE4R) reaktif boyar maddesini seçmiştir. Sonuç olarak, sadece ultrases ile $253 \mathrm{kHz}$ frekansta, \% 80.62; US/ aktif karbon ile $25.67 \mathrm{kHz}$ frekansta \% 99.9 renk, \% 85.22 KOİ giderimi elde edilmiştir.

Liu ve ark. [31], Acid orange 7 boyası bulunan bir atıksuyun US+ Fe $e^{0}$ GAC (granül aktif karbon) ile giderimi üzerine yapılan deneyler sonucunda, US ile yapılan arıtımın daha verimli olduğunu tespit etmişlerdir.

Stucci ve ark. [32], US destekli $\mathrm{TiO}_{2}$ ile asetominofen ve amoksilisin adsorpsiyonu üzerine gerçekleştirdikleri çalışmalarında, $\mathrm{Mn}-\mathrm{TiO}_{2}$ ile Asetominofen \% 52, Amoksilisin \% 94 giderimi gerçekleştirmişlerdir.

Low ve Tan [33], pomelo meyvesinin kabuklarıyla sulu çözeltilerden metilen mavisi giderimi yaptıkları çalışmalarında ultrases ile bir ön arıtım gerçekleştirmişlerdir. En yüksek adsorpsiyonun \% 30 'luk ultrases genliğinde sağlandığı ve US'nin ön işlem olarak kullanılmasının aynı anda kullanılmasına göre daha etkili olduğu sonucuna varılmıştır.

\subsection{Son Yıllardaki Ultrases Işınımının Atıksu Arıtımındaki Diğer Uygulamaları}

Yukarıdaki bölümlerde anlatılanlara ek olarak, ultrases ile atıksu arıtımı uygulamalarında farklı yöntemlerde geliştirilmiştir.

Şahinkaya, reaktif orange 16 (RO 16) boyasının, sonikasyon aracılığıyla ferrat (VI) oksidasyonu üzerine iki aşamalı bir çalışma gerçekleştirmiştir. İlk aşamada $\mathrm{pH}=7,\left[\mathrm{~K}_{2} \mathrm{FeO}_{4}\right]=50 \mathrm{mg} / \mathrm{L}$ koşullarında yalnızca ferrat (VI) oksidasyonu metodu uygulamış ve \% 85 boyar madde giderim verimi elde etmiştir. İkinci aşamada aynı optimum koşullarda $20 \mathrm{kHz}$ sabit frekansı ekleyerek verimin \% 91 değerine çıktığını tespit etmiştir [5].

Ergün, yapmış olduğu bir çalışmada, elektrokoagülasyon, ultrases ve ikisinin kombinasyonunu kullanarak levafix scarlet E2GA (LSE2) ve levafix yellow E-3RL (LYE3) boyalarının sulu solüsyonlardan giderimi üzerine karşılaştırma yapmıştır. Birinci boyar madde olan LSE2'nin elektrokoagülasyon (EC), ultrases (US) ve EC + US yöntemleriyle giderimini sırasıyla, \% 99.9, \% 42, \% 99.2 olarak bulmuştur. LYE3 boyasının gideriminde ise aynı sırayla; \% 95.8, \% 44.1 ve \% 97.2 değerlerini elde etmiştir [6]. 
İçme suyu dezenfeksiyonu için ultrasesin kullanıldığı bir çalışmada, US/klorlama yapılarak, hem suyun dezenfekte edilmesi hem de dezenfeksiyon yan ürünlerinin oluşmasının engellenmesi amaçlanmıştır. İndikatör bakteri olarak; Escherichia coli (E. coli), Bacillus subtilis (B. subtilis), and Staphylococcus aureus (S. aureus) seçilmiştir. Bu amaçla, tek ve çift frekanslarda US denenmiştir. Klor kaynağı olarak ise NaClO kullanılmıştır. En fazla bakteri gideriminin 17+ $33 \mathrm{kHz}$ frekansında gerçekleştiği tespit edilmiştir [34].

\section{Sonuç}

Ultrases teknolojisi uzun yıllardan beri farklı disiplinlerde kullanılan bir yöntemdir. Çevre mühendisliği uygulamaları özellikle son yıllarda ivme kazanmıştır. $\mathrm{Bu}$ teknolojiden, atıksu arıtımı, dezenfeksiyon, alg giderimi [2] ve sentezleme işleminde yardımcı etken olarak kullanımı gibi birçok alanda yaygın olarak yararlanılmaktadır. Tek başına su arıtımında kullanılabildiği gibi başka proseslerle birleştirilerek kullanılabilmektedir. Başka proseslerle kombine edildiğinde atıksu arıtım veriminin arttığı birçok çalışmada görülmektedir. Sonuç olarak ultrases yöntemi fazladan kimyasal ilavesi gerektirmeyen, uygulaması basit, temiz bir yöntemdir. Gelecek çalışmalarda, çevre mühendisliği uygulamalarında farklı kombinasyonlarla çeşitli kirleticilerin gideriminde kullanılacağı düşünülmektedir.

\section{Kaynaklar}

[1] Ildırar, D., “ Maya Endüstrisi Atıksuyunun Ultrases İle Koyu Renginin Giderilmesi” Hitit Üniversitesi, Fen Bilimleri Enstitüsü, Yüksek Lisans Tezi, 16s, Çorum, 2014

[2] Esmer H. E., Kaymak G., Tartar Ş., Kayhan F. E., “ Su Arıtımında Ultrases Uygulaması: Arıtma Yöntemlerine Farklı Bir Yaklaşım “ Çanakkale Onsekiz Mart Üniversitesi Fen Bilimleri Enstitüsü Dergisi, 2 (1), 84-110, 2016

[3] Edecan, M. E., “ Kombine Ultrases/Aktif Karbon Kullanarak Tekstil Boyar Maddesinin Renk Gideriminin Modellenmesi Ve Optimizasyonu “ Atatürk Üniversitesi, Fen Bilimleri Enstitüsü, Yüksek Lisans Tezi, 14s, Erzurum, 2006

[4] Vajnhandl S., Le Marechal A. M., " Ultrasound in textile dyeing and the decolouration/mineralization of textile dyes” Dyes and Pigments, 65(2), 89-101, 2005

[5] Şahinkaya, S., “ Decolorization of reactive orange 16 via ferrate(VI) oxidation assisted by sonication” Turkish Journal of Chemistry, 41(4), 577-586, 2017

[6] Ergün, G., “ Bazı Tekstil Boyar Maddelerin Sulu Çözeltilerden Elektrokoagülasyon Ve Ultrases Yöntemlerini Kullanarak Giderimi”, Gebze Yüksek Teknoloji Enstitüsü Mühendislik Ve Fen Bilimleri Enstitüsü, Yüksek Lisans Tezi, 58-59s, Gebze, 2013

[7] Bire, M., "İleri Oksidasyon Yöntemleriyle (Uv, Ultrases, Katalizör) Atık Sulardan Boyar Madde Giderimi”, Atatürk Üniversitesi, Fen Bilimleri Enstitüsü, Yüksek Lisans Tezi, 20s, Erzurum, 2011

[8] Gümüşdere, H. K., “ Zararlı Organik Bileşiklerin Bozundurulmasına Ses Ötesi Dalgaların (Ultrasound) Etkisi”, Ankara Üniversitesi, Fen Bilimleri Enstitüsü, Yüksek Lisans Tezi, is, Ankara, 2007

[9] Mason, T. J., Joyce, E., Phull, S. S., Lorimer, J. P. "Potential uses of ultrasound in the biological decontamination of water”, Ultrasonics sonochemistry, 10(6), 319-323, 2003

[10] Estévez-Calvar, N., Gambardella, C., Miraglia, F., Pavanello, G., Greco, G., Faimali, M., Garaventa, F., "Potential use of an ultrasound antifouling technology as a ballast water treatment system”, Journal of Sea Research, 133, 115-123, 2018 
[11] Gogate, P. R., Pandit, A. B., "A review of imperative technologies for wastewater treatment II: hybrid methods." Advances in Environmental Research, 8 (3-4), 553-597, 2004

[12] Jing, L., Chen, B., Wen, D., Zheng, J., Zhang, B., “Pilot-scale treatment of atrazine production wastewater by UV/O3/ultrasound: Factor effects and system optimization”, Journal of environmental management, 203, 182-190, 2017

[13] Jawale, R. H., Tandale, A., Gogate, P. R. “ Novel approaches based on ultrasound for treatment of wastewater containing potassium ferrocyanide” Ultrasonics Sonochemistry, 38, 402-409, 2017

[14] Guo, W. Q., Yin, R. L., Zhou, X. J., Du, J. S., Cao, H. O., Yang, S. S., Ren, N. Q., "Sulfamethoxazole degradation by ultrasound/ozone oxidation process in water: kinetics, mechanisms, and pathways", Ultrasonics sonochemistry, 22, 182-187, 2015

[15] Barik, A. J., Gogate, P. R., "Degradation of 2, 4-dichlorophenol using combined approach based on ultrasound, ozone and catalyst” Ultrasonics sonochemistry, 36, 517-526, 2017

[16] Nakajima, A., Tanaka, M., Kameshima, Y., \& Okada, K., "Sonophotocatalytic destruction of 1, 4-dioxane in aqueous systems by HF-treated TiO2 powder”, Journal of Photochemistry and Photobiology A: Chemistry, 167(2-3), 75-79, 2004

[17] Reddy, D. R., Dinesh, G. K., Anandan, S., Sivasankar, T.,” Sonophotocatalytic treatment of Naphthol Blue Black dye and real textile wastewater using synthesized Fe doped TiO2”, Chemical Engineering and Processing: Process Intensification, 99, 10-18, 2016

[18] Verma, A., Kaur, H., Dixit, D.,” Photocatalytic, sonolytic and sonophotocatalytic degradation of 4-chloro-2nitro phenol”, Archives of Environmental Protection, 39(2), 17-28, 2013

[19] Şahinkaya, S., "COD and color removal from synthetic textile wastewater by ultrasound assisted electroFenton oxidation process”, Journal of Industrial and Engineering Chemistry, 19, 601-605, 2013

[20] Hassani, A., Karaca, C., Karaca, S., Khataee, A., Açışlı, Ö., Yılmaz, B.,” Enhanced removal of basic violet 10 by heterogeneous sono-Fenton process using magnetite nanoparticles”, Ultrasonics Sonochemistry, 42, 390402, 2018

[21] Giray, S. N., “ Kumaş Boyaması Yapan Kahramanmaraş Tekstil Fabrikaları Atıksularını Ultrases Fenton Ve Fenton Oksidasyonuyla Arıtımının Araştırılması”, Kahramanmaraş Sütçü İmam Üniversitesi, Fen Bilimleri Enstitüsü, Yüksek Lisans Tezi, 75s, Kahramanmaraş, 2014

[22] Zhang, H., Fu, H., Zhang, D., "Degradation of CI Acid Orange 7 by ultrasound enhanced heterogeneous Fenton-like process”, Journal of Hazardous Materials, 172(2-3), 654-660, 2009

[23] Adityosulindro, S., Barthe, L., González-Labrada, K., Haza, U. J. J., Delmas, H., Julcour, C.,”Sonolysis and sono-Fenton oxidation for removal of ibuprofen in (waste) water", Ultrasonics sonochemistry, 39, 889-896, 2017

[24] Şahinkaya, S., Kalıpcı, E., Öztürk M., “ As (III)’ün As (V)’e Ultrasonik Oksidasyonu”, Nevşehir Üniversitesi Fen Bilimleri Enstitüsü Dergisi, 2 (1), 103-108, 2013

[25] Neppolian, B., Doronila, A., Ashokkumar, M., "Sonochemical oxidation of arsenic (III) to arsenic (V) using potassium peroxydisulfate as an oxidizing agent”, Water research, 44(12), 3687-3695, 2010

[26] Barzegar, G., Jorfi, S., Zarezade, V., Khatebasreh, M., Mehdipour, F., Ghanbari, F., "4-Chlorophenol degradation using ultrasound/peroxymonosulfate/nanoscale zero valent iron: Reusability, identification of degradation intermediates and potential application for real wastewater”, Chemosphere, 201, 370-379, 2018

[27] Gonze, E., Fourel, L., Gonthier, Y., Boldo, P., Bernis, A.,” Wastewater pretreatment with ultrasonic irradiation to reduce toxicity”, Chemical Engineering Journal, 73(2), 93-100, 1999 
[28] Khaire, R. A., Gogate, P. R.”’ Intensified Recovery of Lactose from Whey using Thermal, Ultrasonic and Thermosonication Pretreatments”, Journal of Food Engineering, 2018

[29] İleri, B., "Ultrases Prosesi ile Modifiye Edilen Uçucu Kül Kullanılarak Metil Kırmızısı Boyasının Adsorpsiyon Prosesi ile Giderimi" Dokuz Eylül Üniversitesi Mühendislik Fakültesi Fen ve Mühendislik Dergisi, 21 (61), 25-40, 2019

[30] Şayan, E., "Optimization and modeling of decolorization and COD reduction of reactive dye solutions by ultrasound-assisted adsorption”, Chemical Engineering Journal, 119(2-3), 175-181, 2006

[31] Liu, H., Li, G., Qu, J., Liu, H., “Degradation of azo dye Acid Orange 7 in water by Fe0/granular activated carbon system in the presence of ultrasound”, Journal of Hazardous Materials, 144 (1-2), 180-186, 2007

[32] Stucchi, M., Elfiad, A., Rigamonti, M., Khan, H., Boffito, D. C.” Water treatment: Mn-TiO2 synthesized by ultrasound with increased aromatics adsorption”, Ultrasonics sonochemistry, 44, 272-279, 2018

[33] Low, S. K., Tan, M. C.,’Dye adsorption characteristic of ultrasound pre-treated pomelo peel”, Journal of Environmental Chemical Engineering, 6(2), 3502-3509, 2018

[34] Zou, H. Tang, H. "Comparison of Different Bacteria Inactivation by a Novel Continuous-Flow Ultrasound/Chlorination Water Treatment System in a Pilot Scale." Water, 11(2), 258, 2019

\section{Extended Abstract}

\section{Introduction}

The purpose of this study is to give information about the usage areas of ultrasound radiation, which is a clean technology in the treatment of wastewater which has an important place in terms of environmental pollution. In this respect, some studies using ultrasound radiation alone and in combination (Fenton + US, UV + US, adsorption + US, US $+\mathrm{H}_{2} \mathrm{O}_{2} / \mathrm{O}_{3}$ ) were explained and some studies in related fields were evaluated. According to the evaluations made, ultrasound radiation has been found to increase efficiency in many areas.

Ultrasonic waves need a flexible environment for their propagation as well as being able to focus on electromagnetic waves, fracture, reflection, and this acoustic energy cannot be absorbed by molecules [4]. Sonication is also used in interdisciplinary applications as well as removal of toxic and hazardous compounds from contaminated water. By sonication applications, radicals with high oxidation capacity are formed in the environment and thermal decomposition of volatile hydrophobic compounds in the bubbles occurs [5]. There are four theories regarding the chemical events occurring in the sonication event. These theories are: i) hot spot theory, ii) electric field theory, iii) plasma theory, iv) supercritical theory. Hot spot theory is the formation of high pressure $(1000 \mathrm{~atm})$ and high temperature $\left(5000 \mathrm{~K}^{\circ}\right)$ with the explosion of bubbles. The theory of electricity is based on the break-up of the bubbles and the formation of a high electric field difference. In plasma field theory, microplasms are formed in bubbles. In supercritical theory, ambient conditions are above the critical conditions of water $\left(674 \mathrm{~K}^{\circ}, 22.1 \mathrm{MPa}\right)$ and supercritical water formation occurs by the disintegration of the bubbles [6].

Ultrasonic processes and water decomposition reactions are as follows: Equation (1-10) [7]:

$$
\begin{aligned}
& \cdot \mathrm{OH}+\cdot \cdot \mathrm{OH} \rightarrow \mathrm{H}_{2} \mathrm{O}_{2} \\
& \cdot \mathrm{OH}+\cdot \cdot \mathrm{OH} \rightarrow \mathrm{H}_{2} \mathrm{O}+\mathrm{O} \\
& \cdot \mathrm{OH}+\cdot \cdot \mathrm{OH} \rightarrow \mathrm{H}_{2}+\mathrm{O}_{2} \\
& \cdot \mathrm{H}+\mathrm{O}_{2} \rightarrow \cdot \mathrm{HO}_{2} \\
& \cdot \mathrm{HO}_{2}+\cdot \mathrm{H} \rightarrow \cdot \mathrm{H}_{2} \mathrm{O}_{2} \\
& \cdot \mathrm{HO}_{2}+\cdot \mathrm{HO}_{2} \rightarrow \mathrm{H}_{2} \mathrm{O}_{2}+\mathrm{O}_{2} \\
& \cdot \mathrm{OH}+\mathrm{H}_{2} \mathrm{O} \rightarrow \mathrm{H}_{2} \mathrm{O}_{2}+\mathrm{O} \\
& \cdot \mathrm{H}_{2} \mathrm{O}+\cdot \mathrm{O} \rightarrow \mathrm{H}_{2} \mathrm{O}_{2} \\
& \cdot \mathrm{H}+\cdot \cdot \mathrm{H} \rightarrow \mathrm{H}_{2}
\end{aligned}
$$


$\cdot \mathrm{H}+\cdot \mathrm{OH} \rightarrow \mathrm{H}_{2} \mathrm{O}$

Method

In this study, a review study was carried out by referring to the application of ultrasound radiation in wastewater treatment in environmental engineering. In this context, different applications where ultrasound radiation is used are evaluated. Firstly, the methods have been explained, then different studies about this subject have been exemplified. The ultrasound applications mentioned in this study are: Oxidation with ultrasound, ultrasound + hydrogen peroxide / ozone, sonophotocatalytic oxidation, ultrasound + Fenton, ultrasound + adsorption, ultrasound in pre-treatment and other ultrasound applications. Furthermore, applicability of ultrasound radiation for different wastewaters has been determined.

\section{Results and Discussion}

Firstly, in this study on the examination of the wastewater applications of ultrasound radiation, the usage areas of ultrasound radiation are categorized. Then each method is explained separately and the previous studies made in that subject are compared. It has been found that the application of ultrasound has increased the efficiency significantly in many studies. Ultrasound radiation, when used alone, as well as some other processes (such as Fenton, $\mathrm{H}_{2} \mathrm{O}_{2}, \mathrm{UV}$ ), is highly elevated. When these applications are examined, it is found that most of the treatment systems have a yield of over $90 \%$. Despite the ease of application in laboratory-scale operations, the high initial cost of operation in large installations and electricity costs are seen as a handicap for ultrasound radiation. However, with the developing technology, it is considered that the use of ultrasound radiation in large-scale installations will become easier. In addition, it is thought that this study will benefit the future ultrasound studies. 